\title{
Mixed Integer Programming for HVACs Operation
}

\author{
Mohemmed Alhaider, Lingling Fan, Senior Member, IEEE
}

\begin{abstract}
Mixed integer programming (MIP) problems are formulated in this paper to model the operation of residential Heating Ventilation and Air-Conditioning Systems (HVAC). The objective is to minimize the total cost of the HVAC energy consumption under varying electricity prices. A simplified model of a space cooling system considering thermal dynamics is adopted. The optimization problems consider 24 hour operation of HVAC. Comfort/cost trade-off is modeled by introducing a binary variable. The big-M technique is adopted to obtain linear constraints while considering this binary variable. The MIP problems are solved by CPLEX. Simulation results demonstrate the effectiveness of HVAC's ability to respond to varying electricity price.
\end{abstract}

Index Terms-HVACs, Demand response, Thermal energy storage system

\section{INTRODUCTION}

Electricity service providers consider demand response (DR) and demand side management (DSM) programs to better manage the electricity usage patterns of customers [1]-[5]. A large percentage of electrical loads of most commercial facilities, such as large office buildings and hotel, are comprised of lighting and HVACs [6]-[9]. The U.S. Department of Energy estimates that HVAC loads account for $40 \%$ to $60 \%$ of the energy consumption in U.S. commercial and residential buildings [10]. The power consumed by HAVC loads can be controlled manually by the customers or automatically by the appliances.

The objective of this paper is to investigate how to operate HVAC loads to achieve best economic benefits. The scope of the paper is to formulate optimization problems to decide when to turn an HVAC load on and when to turn it off in a 24 hour time horizon for every 15 minutes.

In order to formulate the optimization problems, the dynamic model of an HVAC load is needed. Lu et al developed a state-space model for HVAC in [11] with temperature as states. This model has been applied in [12] to formulate an optimization problem for HVAC operation.

The contributions of the paper include the following two aspects.

1) The formulation of a novel mixed integer linear programming (MILP) problem to investigate the potential benefits of HVAC in demand response. The benefit of this formulation is the ability of solving problems with a large-scale dimension. This formulation is very different from previous demand response research in the literature by adopting mixed integer programming technique. Examples from the previous demand response research include [13], where genetic-algorithm is used. [12] adopted dynamic programming approach. The benefit of MILP formulation is that it can be solved by commercial engines such as CPLEX and can handle a problem with a large dimension of variables. In the case of building management, a building may consist of hundreds of HVAC. Coordinating HVAC to achieve a common goal requires solving an optimization problem with hundreds of decision variables (to turn on/off each HVAC). Using commercial solvers can achieve fast solving speed.

2) Modeling of comfort/cost trade-offs as a binary variable in this mixed integer programming problem. Using the big-M technique, a comfort/cost trade-offs formulation is developed to give residents more flexibility to operate HVACs. Comfort/cost trade-off was discussed in [14]. Stochastic dynamic programming is employed in [14] to solve the operation of HVAC. For our paper, the introduction of a binary variable leads to a new formulation of constraints suitable for MIP problems. Big-M technique is adopted to incorporate this binary variable into constraints and keep the feasible region linear.

The rest of the paper is organized as follows. Section II describes the thermal dynamic model of HVAC. Section III presents the optimization model of HVAC operation. Section IV presents the simulation results. Section $\mathrm{V}$ is the conclusion.

\section{Thermal Dynamics Models of HVAC}

Equivalent thermal dynamic model of a residential HVAC is developed in [11] and described as follows.

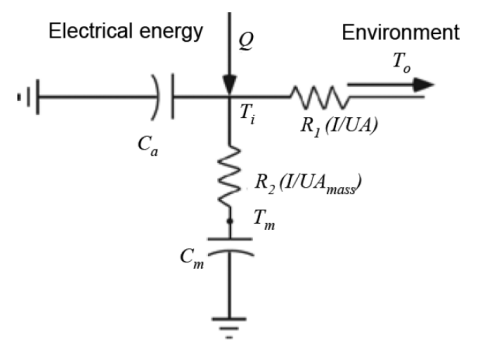

Fig. 1. The equivalent thermal model for HVAC.

In Fig. 1, the notations of the symbols are listed as follows. $Q$ refers to heat rate for HVAC unit (Btu/hr or W)

$U A$ refers to standby heat loss coefficient $\left(\mathrm{Btu} /{ }^{\circ} \mathrm{F} . \mathrm{hr}\right.$ or $\left.W /{ }^{\circ} \mathrm{C}\right)$

$R_{1}$ refers to $1 / \mathrm{UA}$

$R_{2}$ refers to $1 / U A_{\text {mass }}$

$T_{o}$ refers to ambient temperature $\left({ }^{\circ} \mathrm{F}\right.$ or $\left.{ }^{\circ} \mathrm{C}\right)$

$T_{i}$ refers to air temperature inside the house $\left({ }^{\circ} \mathrm{F}\right.$ or $\left.{ }^{\circ} \mathrm{C}\right)$

$T_{m}$ refers to mass temperature inside the house $\left({ }^{\circ} \mathrm{F}\right.$ or $\left.{ }^{\circ} \mathrm{C}\right)$

$C_{a}$ refers to air heat capacity $\left(\mathrm{Btu} /{ }^{\circ} \mathrm{F}\right.$ or $\left.J /{ }^{\circ} \mathrm{C}\right)$

$C_{m}$ refers to mass heat capacity $\left(\mathrm{Btu} /{ }^{\circ} \mathrm{F}\right.$ or $J /{ }^{\circ} \mathrm{C}$ ) 
A state-space description of the equvalent thermal parameters (ETP) model is

$$
\begin{aligned}
& \dot{x}=A x+B u \\
& y=C x+D u \\
& x=\left[\begin{array}{c}
T_{i} \\
T_{m}
\end{array}\right]
\end{aligned}
$$

where

$$
\begin{aligned}
A & =\left[\begin{array}{cc}
-\left(\frac{1}{R_{2} C_{a}}+\frac{1}{R_{1} C_{a}}\right) & \frac{1}{R_{2} C_{a}} \\
\frac{1}{R_{2} C_{m}} & -\left(\frac{1}{R_{2} C_{m}}\right)
\end{array}\right] \\
B & =\left[\begin{array}{c}
\frac{T_{0}}{R_{1} C_{a}}+\frac{Q}{C_{a}} \\
0
\end{array}\right] \\
C & =\left[\begin{array}{ll}
1 & 0 \\
0 & 1
\end{array}\right] \\
D & =\left[\begin{array}{l}
0 \\
0
\end{array}\right]
\end{aligned}
$$

This model is further simplified and used in [15] to model a space cooling unit. The parameters of the model are obtained by matching the measured turn-on time and turn-off time under a range of ambient temperatures. The simplified model is adopted in this paper.

When the cooler is turned OFF, the room temperature at time is described by

$$
T_{\text {room }}^{j+1}=T_{o}^{j+1}-\left(T_{o}^{j+1}-T_{\text {room }}^{j}\right) e^{-\Delta t / R C}
$$

When the cooler is turned $\mathrm{ON}$, the room temperature at time is described by

$$
T_{\text {room }}^{j+1}=T_{o}^{j+1}+Q R-\left(T_{o}^{j+1}+Q R-T_{\text {room }}^{j}\right) e^{-\Delta t / R C}
$$

where $j \quad$ refers to the $j$-th period

$T_{\text {room }}$ refers to room temperature $\left({ }^{\circ} \mathrm{F}\right.$ or $\left.{ }^{o} \mathrm{C}\right)$

$T_{o} \quad$ refers to the ambient temperature or outside temperature

$C$ refers to equivalent heat capacity $\left(\mathrm{Btu} /{ }^{\circ} \mathrm{F}\right)$

$R$ refers to equivalent thermal resistance $\left({ }^{\circ} \mathrm{C} / \mathrm{W}\right)$

$Q \quad$ refers to equivalent heat rate $(\mathrm{W})$

$\Delta t \quad$ refers time step (1 minute)

\section{OPtimizATION MODELS FOR HVAC OPERATION}

Two types of operation of HVAC are modeled. In the first case, HVAC loads will respond to a varying price. In the second case, HVAC loads not only respond to a varying price but also consider the comfort/cost tradeoff. The planning horizon of the house resident is dircretized into time periods $n=1, \cdot N(N=96$ and $\Delta t=15$ minutes $)$ and the continuous thermal dynamics of HVAC model are discretized accordingly.

\section{A. HVAC Responding to a Varying Price}

The optimization model is developed based on the assumption that the HVACs are turned on/off to respond to a varying energy price and to satisfy all comfort and thermal settings. The decision variable vector are denoted as $X$.

$X=\left[P_{i n, 1}, W_{1}^{1}, \cdots, W_{1}^{k}, \cdots, W_{1}^{m}, \cdots, P_{i n, j}, \cdots, W_{j}^{k}, \cdots\right]$

where:

$j \quad$ refers to $j$ th period

$k$ refers to $k$ th HVAC unit and the total number is $m$

$P_{i n, j}$ refers to purchased power at the $j$ th period

$W_{j}^{k}$ refers to a binary variable ( 1 if the HVAC $k$ th is on at the $j$ th period and 0 otherwise).

The objective function is to minimize the total cost of consumed power for the entire time horizon.

$$
\min _{W_{j}^{k}} \sum_{j=1}^{N} \lambda_{j} P_{i n, j}
$$

where $\lambda_{j}$ refers to the energy price at the $j$ th period

Two types of constraints are considered. One is the thermal constraints and the other is power balance constraints.

- Thermal Constraints

$$
\begin{aligned}
T_{\text {room }}^{k, j+1}= & T_{o}^{j+1}+W_{j}^{k} Q R-\left(T_{o}^{j+1}\right. \\
& \left.+W_{j} Q R-T_{\text {room }}^{k, j}\right) e^{-\Delta t / R C} \\
T_{\text {min }} \leq & T_{\text {room }}^{k, j+1} \leq T_{\text {max }}
\end{aligned}
$$

(7) represents the dynamics of the room temperature. It is related to the outside temperature and also affected by the on/off status of the HVAC. Note that the introduction of a binary variable $W_{j}^{k}$ to describe the on/off status successfully combined (3) and (4) into one linear equation in terms of $W_{j}^{k}$.

$T_{\min }$ and $T_{\max }$ refer to the setpoints of the HVAC thermostat.

- Power Balance Constraints

$$
\begin{gathered}
P_{i n, j}=\sum_{i=1}^{k} W_{j}^{k} P_{a / c}^{k} \\
P_{\text {min }} \leq P_{i n, j} \leq P_{\max }
\end{gathered}
$$

where: $P_{\min }$ and $P_{\max }$ refer to the limits of the purchased power and $P_{a / c}$ refers to the rated power of each HVAC unit.

\section{B. Comfort/Cost Trade-Off}

In this model, the comfort/cost trade-off is considered in HVAC operation. The optimization model is developed based on the assumption that the HVAC is adjusted to provide optimal comfort/cost trade-offs for the resident based on varying prices of the energy. The resident would define a desired price that he would allow to increase the maximum setpoint of the thermostat in case the energy price is greater than his desired price.

For this model, a new set of binary variables $W_{\alpha}^{k}$ is introduced. This set of variables will be included in the decision variable vector $X . W_{\alpha j}$ refers to a binary variable that is equal to 1 if the energy price is greater than the desired 
price and 0 otherwise

$$
W_{\alpha j}= \begin{cases}1, & \lambda_{\text {desired }} \leq \lambda_{j} \\ 0, & \text { otherwise }\end{cases}
$$

$\lambda_{\text {desired }}$ refers to the desired price which can be paid to purchase power.

The corresponding constraints can be expressed as:

$$
\begin{aligned}
\lambda_{\text {desired }}-\lambda_{j}+M W_{\alpha j} & \geq 0 \\
\lambda_{\text {desired }}-\lambda_{j}-M\left(1-W_{\alpha j}\right) & <0
\end{aligned}
$$

where $M$ referes to a big number. (10) and (11) define constraints that $W_{\alpha j}$ should comply with. If $W_{\alpha}^{k}=1$, then (10) is always be true if $M$ is big enough. According to (11), then $\lambda_{\text {desired }}<\lambda_{j}$ or the energy price at $j$-th time period is higher than the desired. If $W_{\alpha j}=0$, then (11) is always true. According to (10), $\lambda_{\text {desired }} \geq \lambda_{j}$ or the energy price is lower than the desired.

The objective function is to minimize the total cost of the purchased power for the entire time horizon.

$$
\min _{W_{j}^{k}, W_{\alpha j}} \sum_{j=1}^{N} \lambda_{j} P_{i n, j}
$$

The thermal constraints are modified to include the tradeoff of comfort and cost. We assume that if the energy price is higher than the desired, the residents are willing to have their room temperature a few degree $\left(T_{\alpha}\right)$ higher than the maximum. The thermal constraints are expressed as follows.

$$
\begin{aligned}
T_{\text {room }}^{k, j+1} & =T_{o}^{j+1}+W_{j}^{k} Q R-\left(T_{o}^{j+1}\right. \\
& \left.+W_{j} Q R-T_{\text {room }}^{k, j}\right) e^{-\Delta t / R C} \\
T_{\text {min }} & \leq T_{\text {room }}^{j+1} \leq T_{\text {max }}+W_{\alpha j} T_{\alpha}
\end{aligned}
$$

where $T_{\alpha}$ refers to the allowed incremental in the temperature when the energy price is greater than the desired price.

Note the dynamics of the room temperature did not change. The maximum temperature of the room is now modified to include the effect of trade-off.

\section{Case Studies And Numerical Examples}

The study system shown in Fig. 2 consists of six HVAC units (rated at $5 \mathrm{~kW}$ ). HVAC units consume electricity from the grid at a varying price, shown in Fig. 3 during 24 hours. Room temperature should be maintained within a defined range by the consumer. Here, the consumer is to set thermostat point settings to $71 \mathrm{~F}$ as minimum limit and $75 \mathrm{~F}$ as maximum limit. The ambient temperature is shown in Fig. 4. The parameters $C, R$, and $Q$ introduced in the above thermal model are shown in Table I. The base study is to operate the HVACs to satisfy the thermal constraints comfortably and normally without responding to the energy signal price.

TABLE I

PARAMETER VALUes For HVAC

\begin{tabular}{cccc}
\hline & $Q(W)$ & $R(F / W)$ & $C(J / F)$ \\
\hline Values & 400 & 0.1208 & 3599.3 \\
\hline
\end{tabular}

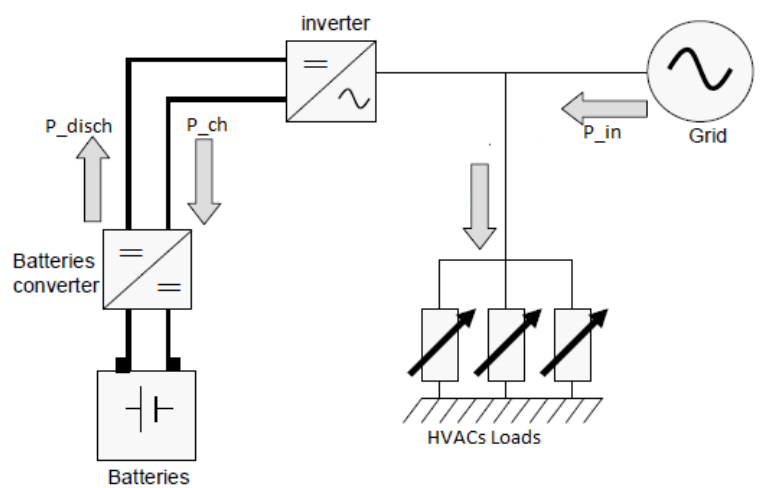

Fig. 2. The study system.

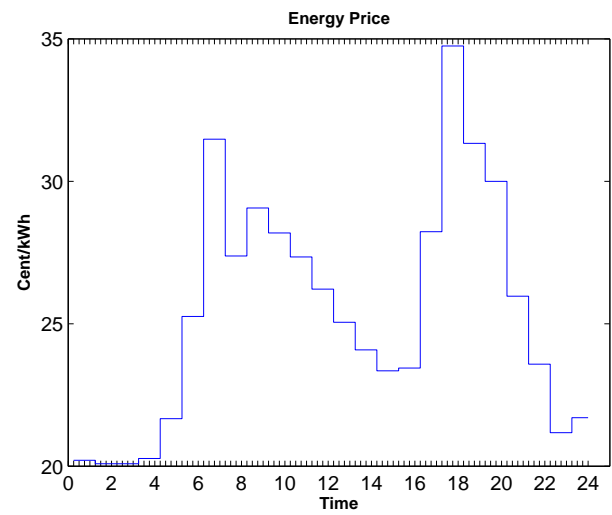

Fig. 3. Energy Price.

\section{A. HVAC Responding to a Varying Price}

In Case-A, we considers operating HVACs while taking the price signal in our considerations. In Case-B, we considers operating HVACs while taking the price signal in our considerations and putting limits on the purchased power $(15 \mathrm{~kW})$. These cases are compared with the base case. Table II shows a comparison of the three cases. It is noticed that the total cost of purchasing energy is reduced from $\$ 18.62$ at the base case to $\$ 17.74$ for Case- $\mathrm{A}$ which represents $4.73 \%$ reduction. For Case- $\mathrm{B}$, the reduction is $4.5 \%$.

Fig. 5 shows a comparison between the load profile in the

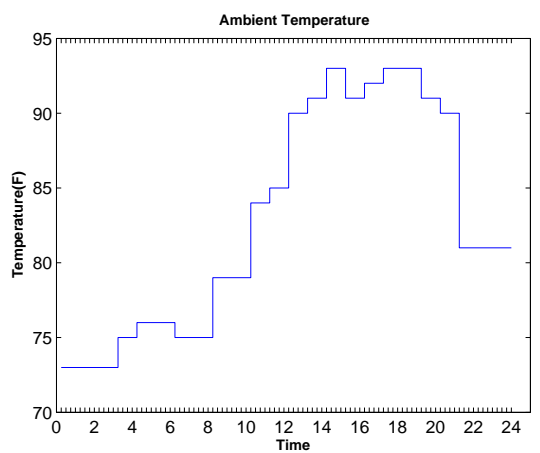

Fig. 4. Ambient Temperature. 
TABLE II

HVACs Behavoirs Considering DyNAMic Price

\begin{tabular}{cccc}
\hline Scenario & $\begin{array}{c}\text { ConsumedEnergy } \\
k W h\end{array}$ & $\begin{array}{c}\text { PeakLoad } \\
k W\end{array}$ & $\begin{array}{c}\text { Cost } \\
\$\end{array}$ \\
\hline Base & 67.5 & 25 & 18.619 \\
Case A & 67.5 & 25 & 17.74 \\
Case B & 67.5 & 15 & 17.791 \\
\hline
\end{tabular}

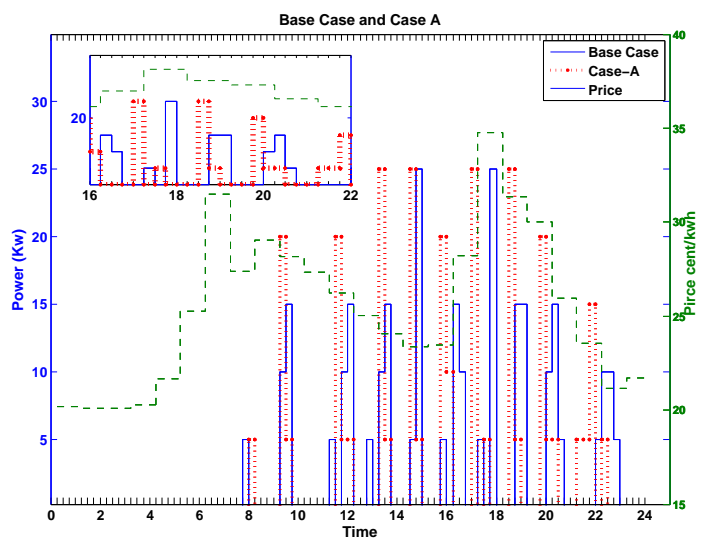

Fig. 5. Loads Profile Comparison between The Base study and Case-A.

base case and Case-A. It is noticed that in Case-A (dotted stairs), the HVAC loads avoid to consume power at the peak price periods while in the base case (solid stairs), the HVAC loads are indifferent to the energy price signal. Fig. 6 shows a comparison between the load profile in Case-A and CaseB. Itis noticed that in Case-B (dotted stairs) the total power consumption has not exceeded $15 \mathrm{~kW}$ which is the power limit of consumption. The peak load $25 \mathrm{~kW}$ in Case-A (solid stairs) is now shaved to $15 \mathrm{~kW}$ in Case-B. All thermal constraints and comfort settings were satisfied while shifting the load in Case-A and shaving the peak in Case-B.

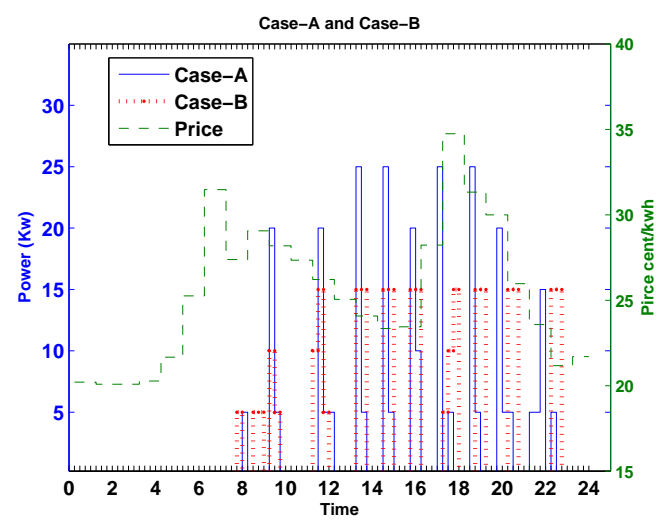

Fig. 6. Loads Profile Comparison between Case-A and Case-B

\section{B. Comfort/Cost Trade-Offs}

In Case- $\mathrm{C}$, we consider the comfort/cost trade-off for consumers. A maximum desired price of purchasing electricity is defined by the consumer. When the energy price exceeds the maximum desired price, the consumer would prefer to allow the maximum temperature setting to be increased by a defined quantity. Here we investigate two different scenarios. In Case$\mathrm{C} 1$ and Case-C2, we set the desired price to be $26 \mathrm{cent} / \mathrm{kWh}$ and assume that we can increase the maximum temperature by 2 degrees and 1 degree, respectively. Changes in the thermostat settings are assumed to be done only on HVAC-1, HVAC-3, and HVAC-5.

Fig.7 presents the result of Case-C1. It shows that when the energy price exceeds the desired price, HVAC-1, HVAC-3, and HVAC-5 respond to this increase by changing the thermostat setting of the maximum temperature. Table. III shows that both energy consumption and total cost are reduced. The cost reduction represent $11.2 \%$ in Case-C1 and $8.5 \%$ in Case-C2.

TABLE III

HVACS BeHAVOIRS CONSIDERING COMFORT/COST TRADE-OFF

\begin{tabular}{cccc}
\hline Scenario & $\begin{array}{c}\text { ConsumedEnergy } \\
k W h\end{array}$ & $\begin{array}{c}\text { PeakLoad } \\
k W\end{array}$ & $\begin{array}{c}\text { Cost } \\
\$\end{array}$ \\
\hline Base & 67.5 & 25 & 18.619 \\
Case C-1 & 63.75 & 25 & 16.736 \\
Case C-2 & 66.25 & 25 & 17.050 \\
\hline
\end{tabular}

\section{CONCLUSION}

In this paper, MIP optimization problems are formulated to determine HVAC loads' on/off status. The objective is to save the cost for 24 hours. HVAC loads respond to a varying energy price and make on/off status decision for each HVAC every 15 minutes to satisfy the temperature requirements and at the same time to save the cost. In addition, the comfort/cost tradeoff is modeled by the introduction of a binary variable and being incorporated into linear constraints using Big-M technique. The MIP optimization problems are solved by CPLEX. Case studies demonstrate the applications of the MIP formulations. Case studies also demonstrate the use of HVAC loads for peak load shaving and price shifting. Cost savings are demonstrated by considering comfort/cost tradeoff. The contributions of the paper lie in modeling of HVAC in demand response programming, including the following two aspects.

1) The formulation of a novel mixed integer programming problem to investigate the potential benefits of HVAC in demand response. This formulation is very different from previous research in the literature by adopting mixed integer programming technique.

2) Modeling of comfort/cost trade-offs as a binary variable in this mixed integer programming problem. Using the big-M technique, a comfort/cost trade-offs formulation is developed to give residents more flexibility to operate HVACs.

\section{REFERENCES}

[1] A. D. Giorgio and L. Pimpinella, "An event driven smart home controller enabling consumer economic saving and automated demand side management," Applied Energy, vol. 96, no. 1, pp. 92 - 103, 2012.

[2] T. Logenthiran, D. Srinivasan, and T. Z. Shun, "Demand side management in smart grid using heuristic optimization," Smart Grid, IEEE Transactions on, vol. 3, no. 3, pp. 1244-1252, 2012.

[3] F. Rahimi and A. Ipakchi, "Overview of demand response under the smart grid and market paradigms," in Innovative Smart Grid Technologies (ISGT), 2010, 2010, pp. 1-7. 

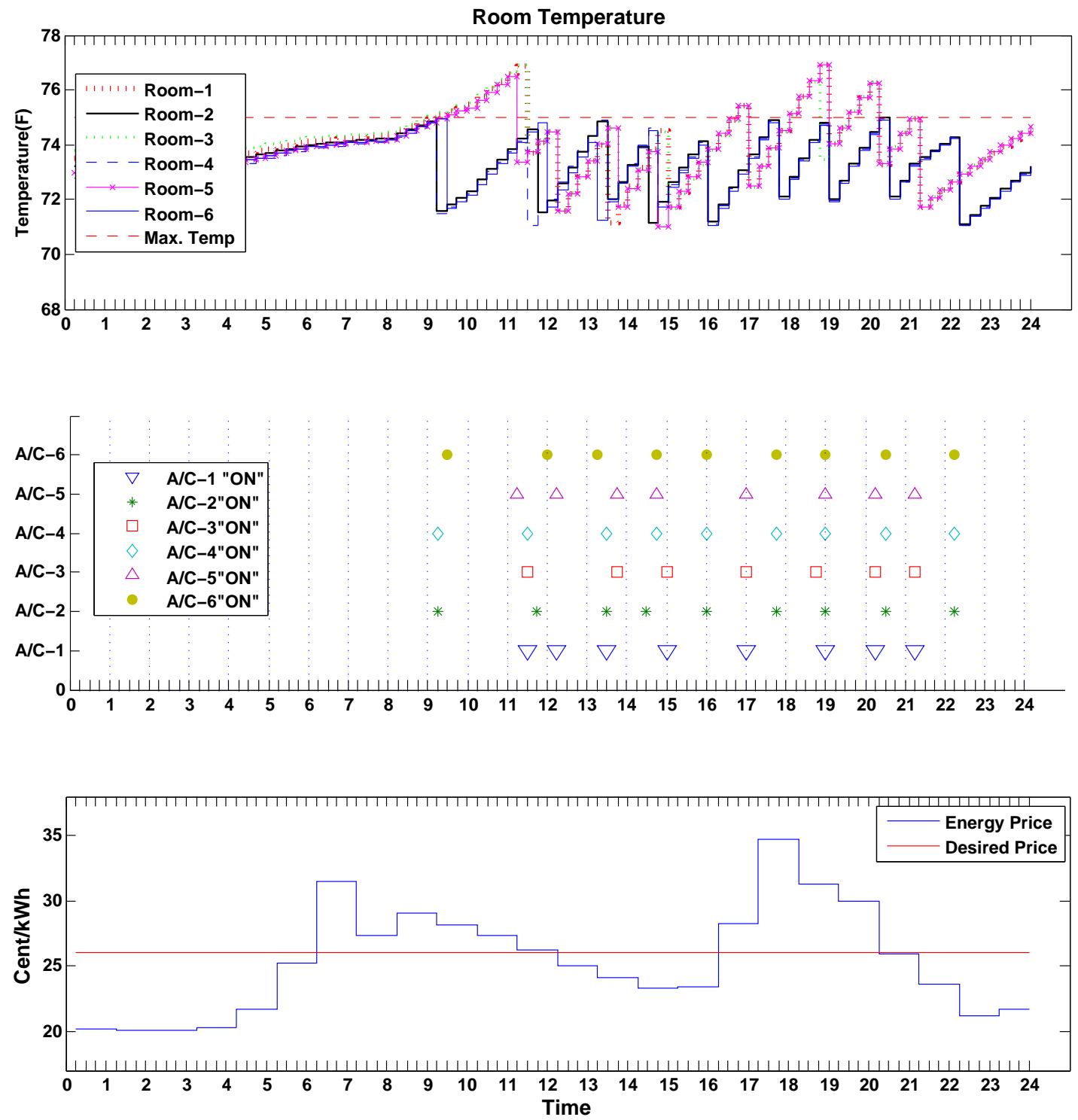

Fig. 7. HVACs Behavoirs Considering Comfort/Cost Trade-Offs Case-C1.

[4] N. Gudi, L. Wang, and V. Devabhaktuni, "A demand side management based simulation platform incorporating heuristic optimization for management of household appliances," International Journal of Electrical Power and Energy Systems, vol. 43, no. 1, pp. 185 - 193, 2012. [Online]. Available: http://www.sciencedirect.com/science/article/pii/S014206151200213X

[5] J. Zhong, C. Kang, and K. Liu, "Demand side management in china," in Power and Energy Society General Meeting, 2010 IEEE, 2010, pp. $1-4$.

[6] M. Meisel, T. Leber, M. Ornetzeder, M. Stachura, A. Schiffleitner, G. Kienesberger, J. Wenninger, and F. Kupzog, "Smart demand response scenarios," in AFRICON, 2011, 2011, pp. 1-6.

[7] S. Gottwalt, W. Ketter, C. Block, J. Collins, and C. Weinhardt, "Demand side managementa simulation of household behavior under variable prices," Energy Policy, vol. 39, no. 12, pp. 8163 - 8174, 2011.

[8] S. Gyamfi and S. Krumdieck, "Scenario analysis of residential demand response at network peak periods," Electric Power Systems Research, vol. 93, no. 0, pp. $32-38,2012$.

[9] M. H. Albadi and E. El-Saadany, "Demand response in electricity markets: An overview," in Power Engineering Society General Meeting, 2007. IEEE, 2007, pp. 1-5.

[10] [Online]. Available: http://www1.eere.energy.gov/buildings/

[11] S. Katipamula and L. NING, "Evaluation of residential hvac control strategies for demand response programs," ASHRAE transactions, pp. 535-546, 2006

[12] P. Du and N. Lu, "Appliance commitment for household load scheduling," Smart Grid, IEEE Transactions on, vol. 2, no. 2, pp. 411-419, 2011.

[13] A. Arabali, M. Ghofrani, M. Etezadi-Amoli, M. S. Fadali, and Y. Baghzouz, "Genetic-algorithm-based optimization approach for energy management," Power Delivery, IEEE Transactions on, vol. 28, no. 1, pp. 162-170, 2013.

[14] A. Thomas, P. Jahangiri, D. Wu, C. Cai, H. Zhao, D. Aliprantis, and L. Tesfatsion, "Intelligent residential air-conditioning system with smartgrid functionality," Smart Grid, IEEE Transactions on, vol. 3, no. 4, pp. 2240-2251, 2012

[15] N. Lu, "An evaluation of the hvac load potential for providing load balancing service," Smart Grid, IEEE Transactions on, vol. 3, no. 3, pp. 1263-1270, 2012. 